\title{
Monográfico: El patrimonio musical en el aula: danza, folclore y flamenco
}

Monographic: Musical heritage in the classroom: dance, folklore and flamenco

\author{
Rosa de las Heras-Fernández \\ rosa.heras@unir.es \\ Departamento de Didáctica de la Música \\ Universidad Internacional de la Rioja \\ Madrid, España \\ ORCID: http://orcid.org/0000-0001-5221-1086
}

doi: 10.7203/LEEME.45.17476

Recibido: 28-05-2020 Aceptado: 28-05-2020. Contacto y correspondencia: Rosa de las Heras Fernández. Departamento de Didáctica de la Música, Universidad Internacional de la Rioja, Facultad de Educación. Calle Almansa, 101, C.P. 28040 Madrid. España.

El patrimonio musical forma parte de los bienes inmateriales que determina la identidad cultural de un colectivo (UNESCO, 2005). El flamenco fue nombrado por la UNESCO (2010) patrimonio cultural inmaterial de la humanidad. La Educación Artística debería tener como reto el conocimiento, conservación y transmisión de la cultura propia y ajena (Siankope y Villa, 2004). Sin embargo, las piezas del folclore, de danza española y flamenco no están tan presente en las aulas a pesar de que se reflejan en diversos objetivos y contenidos de la legislación. ¿Podría el alumno adquirir nociones básicas de cultura sin conocer los elementos fundamentales de la música y la danza más representativos de su país? (Riaño y Cabedo-Mas, 2013). Las aulas deberían ser un lugar para la recuperación y adaptación de repertorio popular, tradicional, para así conservar parte de nuestra cultura, folclore y el flamenco. De esta manera, podría perpetuarse una música y una danza que, actualmente, adolecen de un desconocimiento generalizado (Arévalo, 2009). De esta forma, este número de la revista muestra dos artículos en el ámbito del flamenco y el folclore desde contextos de enseñanza no formal y formal, respectivamente.

El artículo de las Dras. Ramírez-Hurtado y Pérez-Colodrero, "Escuelas de flamenco y diversidad funcional: una mirada desde la inclusión en la ciudad de Granada" aborda la enseñanza del flamenco en Granada en contextos no formales desde un enfoque de diversidad funcional. Una investigación cualitativa que realiza un análisis en profundidad abordando la identificación de la totalidad de escuelas de la ciudad, entrevistas a 13 de sus directoras y profesoras, e historias de vida de 5 de sus estudiantes con diversidad funcional. De esta forma, las autoras presentan un trabajo de forma completa abordando el tema de estudio desde distintas perspectivas. Comienza el manuscrito reflejando las escasas investigaciones en el ámbito del flamenco y cómo éstas se producen en ámbitos no formales. También, aborda la diversidad funcional destaca cómo las artes, y en concreto la música, son un medio ineludible de inclusión para la diversidad funcional, sin necesidad de estar adscrito a la Educación Especial o la Musicoterapia. La metodología cualitativa muestra tres categorías de las escuelas de flamenco en función del tipo de inclusión. El análisis de las entrevistas realizadas a profesores y alumnos señala los beneficios que produce el baile flamenco en el estado de ánimo del alumnado con discapacidad. En las conclusiones del trabajo se extraen, por un lado, que existen 22 escuelas de flamenco en Granada, número elevado con respecto a la población censada y que el alumnado con diversidad funcional ha estado presente en la mayoría de las escuelas. Así, el profesorado ha adaptado la enseñanza a este tipo de alumnado o bien porque tenía formación universitaria

@Rosa de las Heras-Fernández. The content of this article is the sole responsibility of the authors. The Revista Electrónica de LEEME and Universitat de València are not liable for any legal actions that may arise involving the article's content. Revista Electrónica de LEEME - Lista Electrónica Europea de Música en la Educación-, http://ojs.uv.es/index/php/LEEME/index ISSN: 1575-9563. Editores: Universidad de Valencia y Jesús Tejada. Visibilidad de esta revista: SCOPUS, Emerging Sources Citation Index (Clarivate), EBSCO, CINDOC (CSIC), Citefactor, COPAC, Dialnet, DICE (CSIC), DOAJ, e-revistas (CSIC), EBSCO Premier, ERIH+, Gale Cengage Learning, INRECS, IRESIE, LATINDEX, MIAR, OCLC Worldcat, RESH, REDIB, RILM Core Journals, SUDOC, ULRICHS. Esta revista es de acceso libre mediante licencia Creative Commons 4.0 CC by. Política de archivado: etiqueta verde SHERPA-ROMEO. 


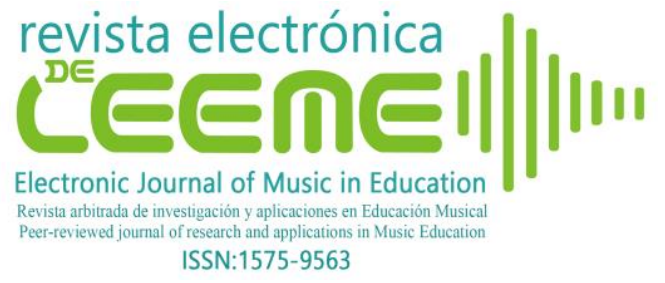

(diferenciadas) o bien porque recibieron formación de personal cualificado (centros segregados o integrados), además de la adaptación empático-intuitiva (escuela pre-inclusivas). Las manifestaciones de las alumnas entrevistadas señalan que la identidad cultural del flamenco es más fuerte que la identidad-discapacidad con lo que cualquier persona puede practicar flamenco y esto nos lleva a decir que el flamenco puede ser un arte inclusivo.

El trabajo de las Dras. Chao-Fernández y Gisbert Caudeli con el Dr. Chao-Fernández abordan el folclore gallego y su importancia de su presencia en las aulas como mejor forma de perpetuar su transmisión. Para el estudio, se aplicó un cuestionario dirigido al profesorado de 400 centros de Educación Primaria de Galicia. La investigación muestra el uso que el profesorado hace de los distintos métodos pedagógico-musicales basados en la revalorización de la música tradicional y folclórica. Los resultados señalan que a pesar de que los métodos mayormente empleados son aquellos que fomentan el uso del folclore, el profesorado asegura que no es con esa finalidad; sin embargo, reconocen que la aportación es mayor cuando se usa el folclore gallego a través de canciones, danzas e instrumentos que si utiliza folclore de otras comunidades o países. Así mismo, en este estudio se analizan los resultados de las entrevistas a 20 docentes de Música. Los resultados ponen de manifiesto que la formación del profesorado con respecto al folclore ha sido escasa. El uso de las canciones se basa fundamentalmente en las que se encuentran en el libro de texto. Los que se atreven a enseñar danzas no eligen las propias del folclore gallego ya sea por desconocimiento o por la dificultad que entrañan. Tampoco utilizan instrumentos del folclore gallego debido a la falta de instrucción sobre su uso. Las conclusiones que arroja este estudio señalan por un lado que el profesorado en su mayoría no contribuye a la conservación y difusión del patrimonio musical gallego, aunque le gustaría hacerlo. Los motivos fundamentales son justificados por la escasa formación musical en este aspecto. Por otro lado, el estudio indica el uso del libro de texto como apoyo fundamental de los contenidos musicales, en los que apenas trabajan en folclore.

Estos artículos tienen en común la revalorización del folclore y del flamenco como estilos musicales que son beneficiosos para la motivación del alumnado, así como, necesarios para la construcción de conocimientos. La impartición de estos estilos musicales suele llevarse a cabo casi exclusivamente por profesionales en contextos no formales. Por este motivo, es necesaria la formación de maestros y profesores a este respecto, con el objetivo de que el folclore y el flamenco puedan ser contenidos imprescindibles en las aulas. Así, las enseñanzas formales no estarán exentas de nuestro patrimonio musical y dancístico como parte fundamental de nuestra cultura.

\section{Referencias}

Arévalo, A. (2009). Importancia del folklore musical como práctica educativa. Revista Electrónica de LEEME, 23, 1-14. Recuperado de: https://ojs.uv.es/index.php/LEEME/article/view/9779/9212

Riaño, MaE. y Cabedo-Mas, A. (2013). La importancia del patrimonio musical en el aula. Estudio sobre la opinión del profesorado en educación infantil. Eufonía, 58, 67-78.

Siankope, J. y Villa, O. (2004). Música e interculturalidad. Madrid: Catarata. UNESCO (2005). Convention on the Protection and Promotion of the Diversity of Cultural Expressions.

UNESCO (2010). El flomenco. Recuperado de: https://ich.unesco.org/es/RL/el-flamenco-00363

@Rosa de las Heras-Fernández. The content of this article is the sole responsibility of the authors. The Revista Electrónica de LEEME and Universitat de València are not liable for any legal actions that may arise involving the article's content. Revista Electrónica de LEEME - Lista Electrónica Europea de Música en la Educación-, http://ojs.uv.es/index/php/LEEME/index ISSN: 1575-9563. Editores: Universidad de Valencia y Jesús Tejada. Visibilidad de esta revista: SCOPUS, Emerging Sources Citation Index (Clarivate), EBSCO, CINDOC (CSIC), Citefactor, COPAC, Dialnet, DICE (CSIC), DOAJ, e-revistas (CSIC), EBSCO Premier, ERIH+, Gale Cengage Learning, INRECS, IRESIE, LATINDEX, MIAR, OCLC Worldcat, RESH, REDIB, RILM Core Journals, SUDOC, ULRICHS. Esta revista es de acceso libre mediante licencia Creative Commons 4.0 CC by. Política de archivado: etiqueta verde SHERPA-ROMEO 